\title{
Tangible Technologies for Childhood Education: A Systematic Review
}

\author{
Carina S. González-González ${ }^{1, *} \mathbb{D}$, María D. Guzmán-Franco ${ }^{2} \mathbb{D}$ and Alfonso Infante-Moro ${ }^{3}$ \\ 1 Department of Computer Engineering and Systems, Faculty of Science, Avda. Astrofísico Francisco Sánchez, \\ s/n, University of La Laguna, 38200 San Cristóbal de La Laguna, Tenerife, Spain \\ 2 Department of Pedagogy, Faculty of Education, Psychology and Sports Sciences, Avda. Tres de Marzo s/n, \\ University of Huelva, 21007 Huelva, Spain; maria.guzman@dedu.uhu.es \\ 3 Department of Financial Economics, Accounting and Operations Management, Faculty of Business, \\ Campus of «La Merced» Plaza de la Merced, 11, University of Huelva, 21002 Huelva, Spain; \\ alfonso.infante@decd.uhu.es \\ * Correspondence: carina.gonzalez@ull.edu.es
}

Received: 20 February 2019; Accepted: 20 May 2019; Published: 22 May 2019

\begin{abstract}
This study reviews published scientific literature on the use of tangible technologies in childhood education, in order to (a) identify the what tangible technologies have been used, (b) recognize the educational purposes and uses these technologies of, and (c) present a synthesis of the available empirical evidence on its educational effectiveness. After systematically searching in WoS, 288 relevant articles were located and analyzed using the Science Mapping Analysis Software Tool from 1968 to 2018. Then, 29 relevant papers of the last five years were included in the review study. For each article, we analyze the purpose of the study, the type of tangible technology used, the research method applied, the sample characteristics and the main results observed. The articles reviewed suggest that the main tangible technology used in childhood education is the tablet and literacy (basic and emergent) is the area most studied with promising results.
\end{abstract}

Keywords: tangible technologies; childhood education; systematic Review

\section{Introduction}

Technologies are integrated into the daily lives of people and European households have mobile devices, tablets, game consoles, robots, etc. The ages of use of mobile devices are increasingly reduced, and young children are users of games and digital content. In Europe, 63\% of families allow their children to play with mobile devices and think that they can favor the development of skills (58\%) and improve the creativity of the youngest $(47 \%)[1,2]$.

Research on child-computer interaction has sought to provide children with technology-mediated activities where communication and collaboration are not impeded [3,4]. The challenge for researchers is to move away from personal computing, a paradigm that a user sees by device, with little or no interaction with others. In recent years, researchers like Sherry Turkle [5] have sounded the alarm about how personal devices reduce face-to-face interactions (with family and other important daily interactions), due to the distracting effect caused by mobile phones and tablets in children and adults. The proliferation of mobile devices and their use by children of all ages has opened the debate in families and school environments. In this sense, educators, having overcome the conception of technology as a danger to their development, agree with the scientific community that a responsible, educational, creative, and supervised use of mobile devices can be highly beneficial for the playful opportunities that offer and their potential for the cognitive, social, and emotional development of young children [6]. 
The natural interfaces (NUI) are the most appropriate for the interaction of children because it allows the user to interact with a computer application without using traditional input devices (such as the keyboard, mouse, etc.), but this interaction is done through human or natural capabilities, such as voice, gestures with the hands, movements of the body and face. Among these types of natural interfaces we find tangible interfaces and gestural interfaces [7]. Besides, tangible technologies allow the interaction and manipulation of digital information through physical objects [2]. We found the following related terms; haptic (related with the sense of touch), tactile (perceptible by the sense of touch), and tangible (capable to be perceived by the sense of touch). As tangible technologies we can consider multitouch surfaces, smartphones, tablets, robots, and technologically-enhanced toys, among others [8]. Thus, tangible interfaces achieve a real direct and active manipulation of the digital object, not only of its behavior but of the meaning or representation of the world. Children played individually or collaboratively with manipulative physical objects (blocks, puzzles, jigsaws, etc.) to learn different skills, especially in Mathematics and in early childhood education [9]. According to Piaget's theory of development, direct manipulation of an object supports the development of thought in particular in young children. In addition, tangible technologies can increase the playful learning, engagement and reflection. Also, research has shown that children through tangible technologies can solve problems and manipulate symbolic information, expressing, reflecting, and exploring their own external representations. Some conceptual frameworks for the development of tangible technologies for learning have been created, such as the Child Tangible Interaction (CTI) [10] or the Tangible Learning Design Framework [11]. Embedding interactivity into physical objects, therefore, allows the "best of both worlds" - supporting traditional exploratory play with physical objects that can be extended and enhanced by the interactive power of digital technology. Then, tangible technologies bring promising opportunities for learning [12-15].

For this reason, in this paper we propose to analyze different tangible and gestural technologies for young children used in educational environments for the infantile stage.

The growing potential that tangible and gestural technologies have on the learning in childhood raises important questions for the field. Thus, this study conducts a systematic review to answer the following research questions.

(1) What tangible technologies have been used in childhood education?

(2) What has been the educational use of tangible technologies in childhood?

(3) What pedagogical approach is behind of tangible technologies in childhood education?

This paper is organized as follows. First, we describe the method that we follow to do the systematic review, then the results of the review are presented, and finally, we provide concluding remarks on the main findings of this work.

\section{Method}

We followed a method proposed by Tsafnat [16] for systematic reviews. The method is divided into 3 main phases: preparation, appraisal, and synthesis (Table 1).

For the first analysis the inclusion/exclusion criteria are as follows.

- Quality: Articles peer-review and index (in the Web of Science (WoS): Articles were identified by searching in the Web of Science (WoS). The indexes included in the search were SCI-EXPANDED, SSCI, A\&HCI, CPCI-S, CPCI-SSH, BKCI-S, BKCI-SSH, and ESCI.

- Date: We decided to study from 1968 because the Dynabook [17] was created by Alan Kay: the first tablet for children. So, the studies selected in this study were published from 1968 to 2018.

- Language (English): Databases were filtered and limited by English language and peer reviewed journals.

- Research area: The first redefining included only the specific documents of the research area: Education \& Educational Research. 
- Type of documents: the type of the document selected was "articles".

- Domain: The keywords used in the search were tangible interfaces, gestural interfaces, sensors, robotics, tablets, young children, infancy, and childhood.

For further refinement, we included in the date of search the articles published in the last 5 years (2013-2018). Additionally, we considered the domain relevant articles that (1) focused on the educational use of specific tangible technology in childhood (0-6 years) and (2) as relevance of papers, the article should be cited at least once. Articles were excluded if in the paper (1) the method was not mentioned and/or (2) it covered subjects were not related to childhood education.

The search originally produced a total of 1485 papers. After the first refining by research area the search obtained 288 papers. These papers have been analyzed with SciMAT [18] to find clusters of words (explained below).

The second refining in the search by the last 5 years and the articles without cites produce 47 registers. These papers were organized into Mendeley. After screened 47 abstracts, 18 papers were eliminated because not corresponding to childhood education ( $0-6$ years old). At the end, 29 articles remained for review of final analysis. The full study selection method is presented in Table 1 and the results are shown in Tables 2 and 3.

Table 1. Description of systematic review method applied in this study.

\begin{tabular}{|c|c|c|}
\hline Task & Description & Phase \\
\hline 1. Formulation of review question & $\begin{array}{l}\text { Identification of tangible technologies, educational } \\
\text { uses and main findings in childhood education }\end{array}$ & \multirow{4}{*}{ Preparation } \\
\hline 2. Definition of the protocol & Method and tools (WoS/SciMat/Mendeley) & \\
\hline 3. Definition search strategy & Databases (WoS) and keywords & \\
\hline 4. Search & Find relevant citations (WoS) & \\
\hline 5. Clustering & $\begin{array}{l}\text { Extract relevant terms and categories from } \\
\text { documents (SciMat) }\end{array}$ & \multirow{4}{*}{ Appraisal } \\
\hline 6. Refine and organize & $\begin{array}{l}\text { Extract most relevant citations (WoS) and organize } \\
\text { references (Mendeley) }\end{array}$ & \\
\hline 7. Abstracts & Screen abstracts, remove irrelevant references & \\
\hline 8. Full texts & $\begin{array}{l}\text { Read full texts and extract data associated to the } \\
\text { categories of analysis }\end{array}$ & \\
\hline 9. Data & Analysis and synthesis of extracted data & \multirow{2}{*}{ Synthesis } \\
\hline 10. Review & Final report & \\
\hline
\end{tabular}

Regarding the SciMAT tool, the procedure was as follows; First of all, the raw data were downloaded from WoS as plain text and entered into SciMAT to build the knowledge base for further science mapping analysis; it contains the bibliographic information stored by WoS per each research document. Those words representing the same concept were grouped. Because some documents did not contain any keywords, a manual addition of descriptive keywords matching title words with keywords present in the knowledge base was carried out for completeness purposes. Furthermore, some meaningless keywords in this context, such as stop words or words with a very broad and general meaning were removed. The procedure of analysis in SciMAT is described step-by-step in Figure 1. 

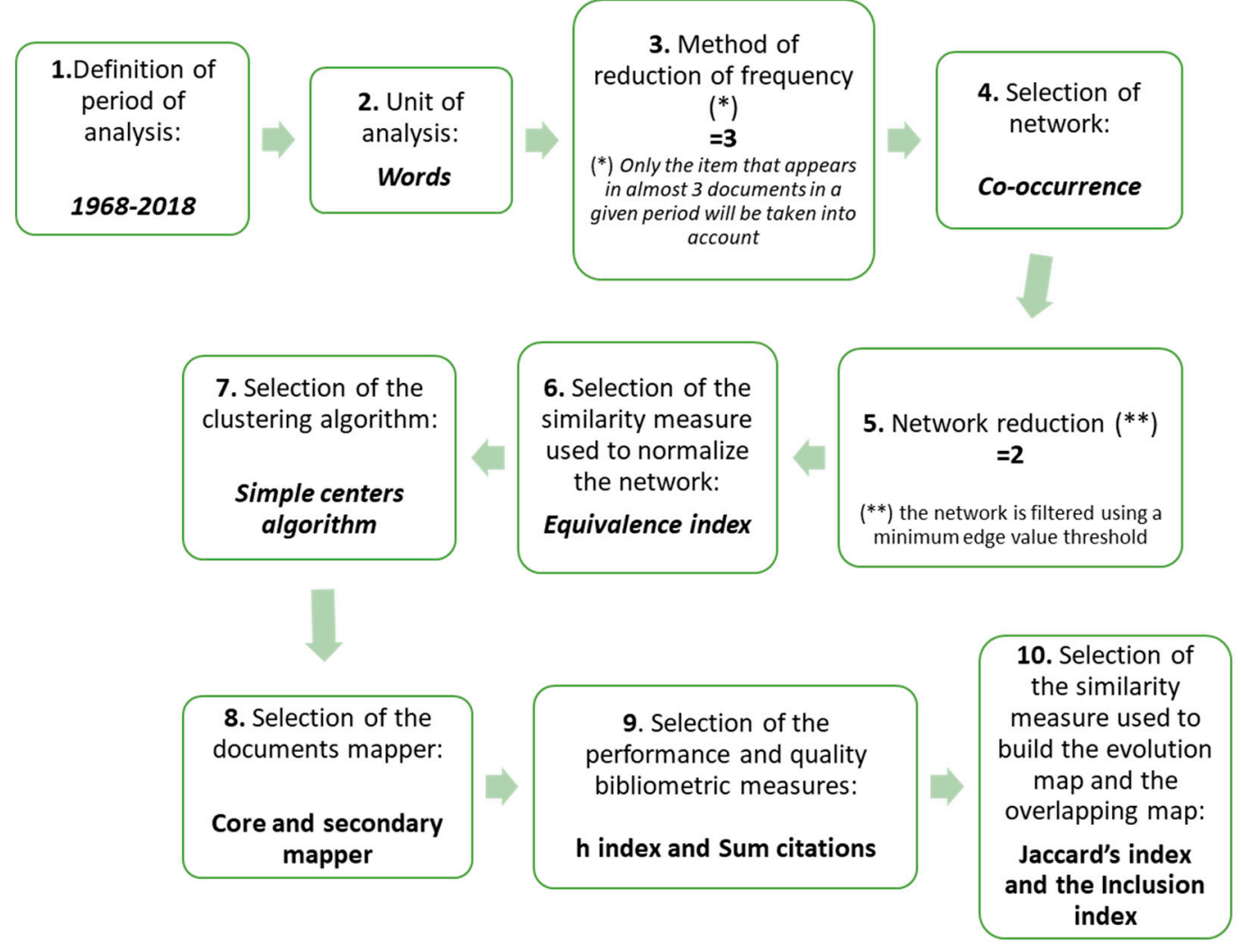

Figure 1. Procedure of analysis followed in SciMAT tool.

In the following section we describe the results that we obtained after the quantitative and qualitative analysis of the documents.

\section{Results}

In this section we present the results of two different analyses of the documents: (a) the quantitative analysis of 288 documents made in the Science Mapping Analysis Software Tool (SciMAT) and (b) the complete qualitative analysis of 29 documents.

\subsection{Science Mapping Analysis (Clustering)}

The number of documents analyzed in the SciMAT was 288 from 1968 to 2018 and corresponding to the tangible technologies of the research area education and educational research. The clusters found in the analysis were the following: digital technologies, coding, literacy, and pedagogical approach (Table 2).

Table 2. Clusters found in the SciMAT analysis.

\begin{tabular}{ccccc}
\hline Cluster $^{\mathbf{1}}$ & Centrality & Centrality Range & Density & Density Range \\
\hline Coding & 24.88 & 0.25 & 46.81 & 1 \\
Digital-Technologies & 41.26 & 1 & 20.21 & 0.5 \\
Literacy & 38.76 & 0.75 & 38.07 & 0.75 \\
Pedagogical Approach & 35.06 & 0.5 & 11.55 & 0.25 \\
\hline
\end{tabular}

${ }^{1}$ Unit of analysis $=$ Words.

The strategic diagram of clusters (Figure 2) shows that "coding" is a highly developed and isolated theme and "literacy" is a motor theme. The "digital technologies" cluster is a central, basic, and transversal theme and the "pedagogical approach" is basic, transversal, emerging, or declining theme. 


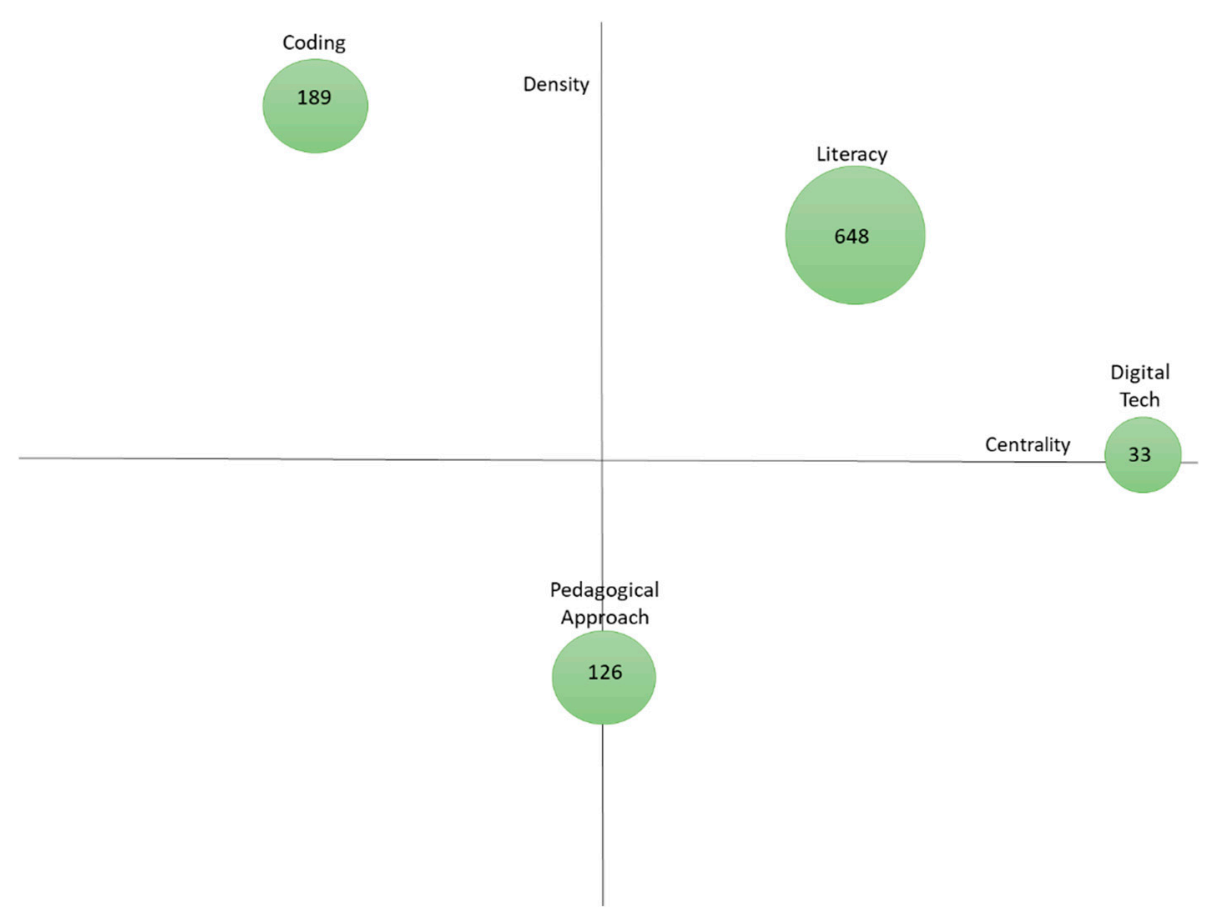

Figure 2. Strategic diagram of core documents (citations count) and meaning.

Figure 3 shows the keywords of a detected theme with its interconnections in a network graph named thematic network or clusters' network. Each thematic/cluster network is labeled using the most significant keyword (central theme). Several keywords are interconnected and the volume of spheres is proportional to the numbers of documents of each keyword, respectively, and the thickness of the link is proportional to the equivalence index. Analyzing the cluster networks of the core documents (Figure 3) we found the set of words most cited around each thematic. Regarding the "digital technologies" subject, the most cited words found in documents are technologies, tablet-computers, text, perspective, and collaboration. In the case of the thematic "coding", the keywords that composed its network are robotic, STEAM, computational thinking, school, and gender. On the thematic of "literacy", the words most cited were early-childhood, Ipads, mobile technologies, touch-screen tablets, and language. Around the "pedagogical approach" area we found the following keywords; game-based learning, special needs, classroom, and motivation. 


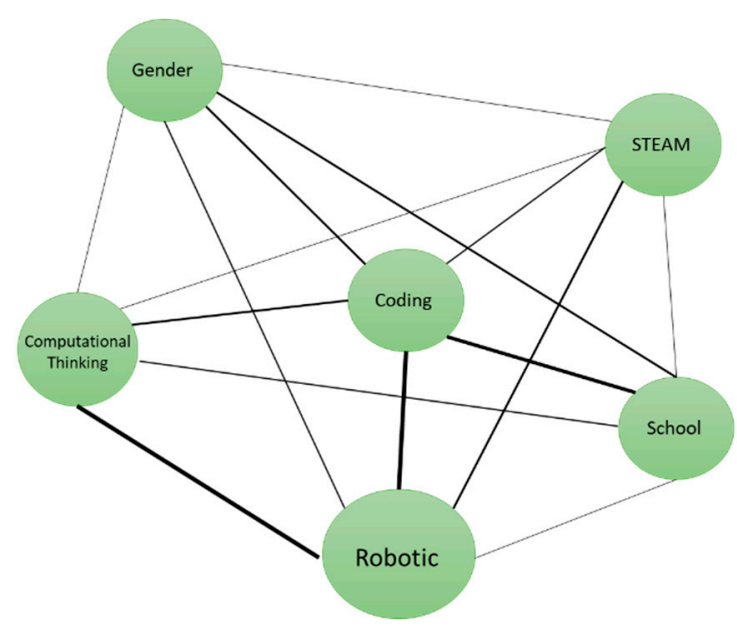

(a) Cluster's network "Coding"

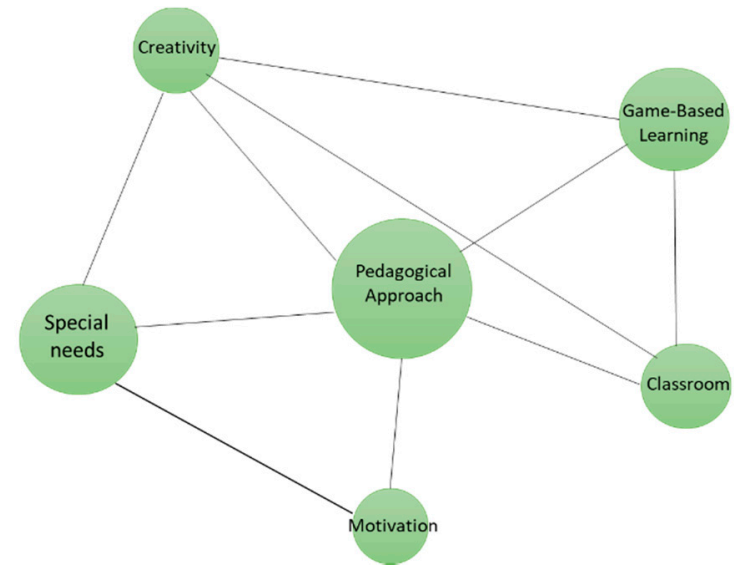

(c) Cluster's network "Coding"

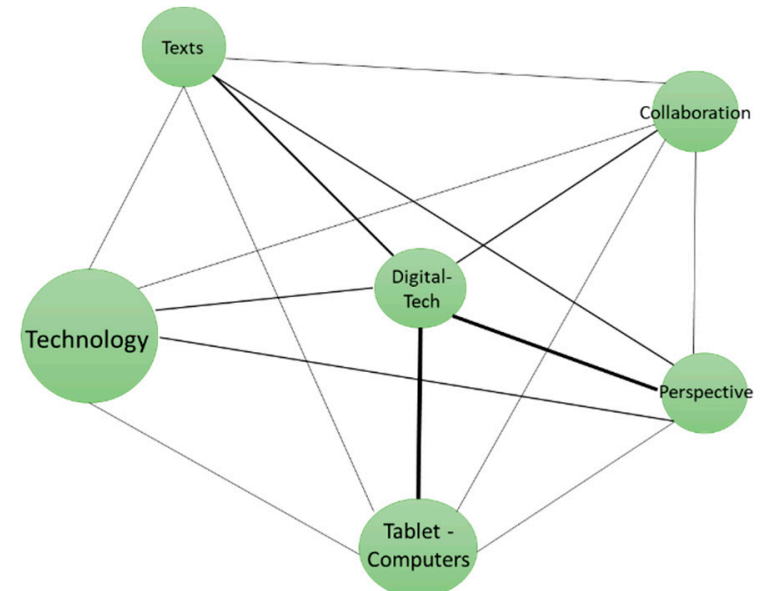

(b) Cluster's network "Digital Technologies"

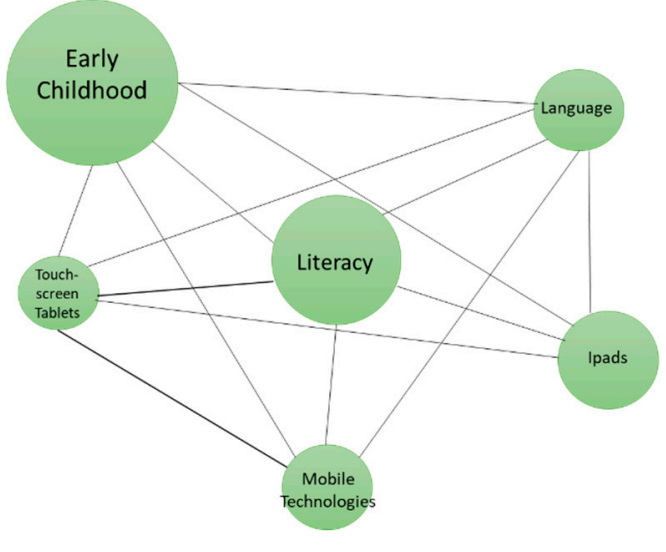

(d) Cluster's network "Digital Technologies"

Figure 3. Cluster networks of core documents (sum citations).

\subsection{Analysis of Documents}

We refined the search by limiting the period of time to the last 5 years and excluding the noncited papers. Then, we organized the papers into Mendeley and screened the abstracts of 47 documents with the purpose to exclude papers not focused on childhood (0-6 years old). Finally, 29 papers were analyzed according to the purpose of the study, the type of technology used, the research method applied, the sample characteristics, and the results observed. Table 3 summarizes the documents analyzed in this section. 
Table 3. Summary of documents analyzed in this study.

\begin{tabular}{|c|c|c|c|c|}
\hline & References & Technology & Sample & Research method \\
\hline \multicolumn{5}{|c|}{ Cluster: Digital Technologies-Research Questions: 1} \\
\hline [19] & $\begin{array}{l}\text { de la Guia, Lopez Camacho, } \\
\text { Orozco-Barbosa Luis and Brea Lujan, } \\
\text { Penichet, \& Lozano Perez, } 2016\end{array}$ & IoT/wearable & $\begin{array}{l}\text { Children: } 15 \\
\text { Age: } 7.33 \text { (mean) }\end{array}$ & Survey/Observation \\
\hline [20] & Marsh, 2017 & Tablets & $\begin{array}{l}\text { Parents (2000) of children aged } 0-5 \text { years } \\
\text { Children: Classroom/A case }\end{array}$ & Survey/Observation \\
\hline [21] & $\begin{array}{l}\text { Gülay Ogelman, Güngör, Körükçü, \& } \\
\text { Erten Sarkaya, } 2018\end{array}$ & $\begin{array}{l}\text { Television, portable computers, } \\
\text { tablets and smartphones }\end{array}$ & $\begin{array}{l}162 \text { children aged between } 5 \text { and } \\
6 \text { years old }\end{array}$ & Questionnaires \\
\hline [22] & Edwards et al., 2018 & Tablets & Children: 70 aged between 4 and 5 years. & Pilot experimental study \\
\hline [23] & Mertala, 2016 & $\begin{array}{l}\text { Computers, tablets, cameras, } \\
\text { television }\end{array}$ & $\begin{array}{l}\text { Children: } 103 \text { aged 5-6 years old from } \\
5 \text { kindergartens. }\end{array}$ & $\begin{array}{l}\text { Children's drawings and tell conversation } \\
\text { method (interviews) }\end{array}$ \\
\hline \multicolumn{5}{|c|}{ Cluster: Coding-Research Questions: 2} \\
\hline [24] & Kanaki \& Kalogiannakis, 2018 & Smartphones & Children aged between $4-8$ years old. & Observation \\
\hline [25] & Elkin, Sullivan, \& Bers, 2016 & Robots & $\begin{array}{c}\text { Children: } 64 \text { aged } 3-5 \text { years old from } \\
7 \text { classrooms. }\end{array}$ & PTD/Observation \\
\hline$[6]$ & Granic et al., 2014 & Robots & $\begin{array}{l}\text { Three teachers and } 53 \text { children aged } \\
\text { between } 4-6 \text { years old. }\end{array}$ & $\begin{array}{l}\text { Iterative testing, analysis, and refinement } \\
\text { of an intervention }\end{array}$ \\
\hline [26] & Alhinty, 2015b & Tablets & 22 children & $\begin{array}{l}\text { Qualitative research (participant } \\
\text { observation, focus groups, semistructured } \\
\text { interviews and blogging) }\end{array}$ \\
\hline \multicolumn{5}{|c|}{ Cluster: Literacy一Research Questions: 2} \\
\hline [27] & $\begin{array}{l}\text { Lu, Ottenbreit-Leftwich, Ding, \& } \\
\text { Glazewski, } 2017\end{array}$ & Tablets & 4 teachers & Observation and Interviews \\
\hline [28] & Neumann, 2018b & Tablets & Children: 48 aged $2-5$ years & Pre-post-test randomized controlled study \\
\hline [29] & Reeves, Gunter, \& Lacey, 2017 & Tablets & $\begin{array}{l}\text { Children: } 28 \text { ( } 4-5 \text { years old) from } \\
2 \text { pre-kindergarten classrooms }\end{array}$ & $\begin{array}{l}\text { VPK Assessment, two groups } \\
\text { (experimental and control) Florida } \\
\text { Department of Education assessment } \\
\text { (FLDOE). }\end{array}$ \\
\hline [30] & Neumann, Finger, \& Neumann, 2017 & E-books and digital games & - & Literature review \\
\hline
\end{tabular}


Table 3. Cont.

\begin{tabular}{|c|c|c|c|c|}
\hline & References & Technology & Sample & Research method \\
\hline [31] & Kervin, 2016 & Tablets & $\begin{array}{l}6 \text { families (12 parents and } 7 \text { preschooler } \\
\text { children) }\end{array}$ & $\begin{array}{c}\text { Qualitative (semistructured interviews and } \\
\text { observations) }\end{array}$ \\
\hline [32] & Neumann \& Neumann, 2017 & Tablets & - & Literature review \\
\hline [33] & Patchan \& Puranik, 2016 & Tablets & $\begin{array}{l}54 \text { preschool children (aged } 41-65 \text { months) } \\
\text { in } 21 \text { small groups }\end{array}$ & $\begin{array}{l}\text { Two individual assessments: letter naming } \\
\text { and letter writing }\end{array}$ \\
\hline [34] & Schacter et al., 2016 & Tablets & Children $=100$ & Randomized controlled trial \\
\hline [35] & Miller \& Warschauer, 2014 & Tablets & - & Literature review \\
\hline [36] & Neumann, 2016 & Tablets & 57 children aged between $2-4$ years old. & Emergent literacy assessment \\
\hline [9] & Neumann, 2014 & Tablets & Parents 109 Children 3-5 years old & $\begin{array}{l}\text { Assessment of children in their preschool } \\
\text { and a home questionnaire for parents. }\end{array}$ \\
\hline [37] & Dunn, Gray, Moffett, \& Mitchell, 2018 & Tablets & 6 children of 5 schools & Focus group \\
\hline \multicolumn{5}{|c|}{ Cluster: Pedagogical Approach. Research Questions: 3} \\
\hline [38] & Kucirkova, 2017 & Tablets & 3 Teachers & Codesign \\
\hline [1] & Blackwell, Lauricella, \& Wartella, 2016b & Tablets & $\begin{array}{l}411 \text { preschool educators serving } \\
\text { 3-5-year-olds in school-based, center-based, } \\
\text { and Head Start preschool programs }\end{array}$ & Survey \\
\hline [9] & Neumann, 2014 & Tablets & 55 parents of children $($ Mena $=3.49$ years $)$ & $\begin{array}{l}\text { Observation/Video } \\
\text { recording/Questionnaire }\end{array}$ \\
\hline \multicolumn{5}{|c|}{ Cluster: Other. Research Questions: 1, 2, 3} \\
\hline [39] & Sullivan \& Bers, 2016b & Robots & 45 children ( $4-7$ years old) & Qualitative interviews (pre-post), Solve-its \\
\hline [40] & Moore \& Adair, 2015 & Tablets & $\begin{array}{l}\text { Pre-kindergarteners and preservice } \\
\text { teachers in early childhood education } \\
\text { coursework }\end{array}$ & Qualitative (Observation) \\
\hline [41] & Arnott, Grogan, \& Duncan, 2016 & Tablets & Children aged $3-5$ years old & Video diaries/Observation \\
\hline [42] & Fleer, 2014 & Tablets & $\begin{array}{c}25 \text { children, range of } 3.3 \text { to } 4.4 \text {; mean of } \\
3.8 \text { years. }\end{array}$ & Video observation \\
\hline [43] & Price, Jewitt, \& Crescenzi, 2015 & Tablets & 11 children of 4 years old & Video observation \\
\hline
\end{tabular}


We grouped the references in four categories according to the previously found clusters: digital technologies, coding, literacy, and pedagogical approach. Also, each category is related to the research questions of this study. Thus, the cluster about digital technologies answers RQ1, the clusters coding and literacy answers RQ2, and the cluster on the pedagogical approach answers RQ3. We added the category "other" for those analyzed documents that focus on other relevant research topics on tangible technologies in childhood education. In the following we describe the references analyzed by category.

\subsubsection{Digital Technologies}

The study found different digital technologies used in early childhood education such as IoT devices and wearables, tablets, and robots. Some authors [19] studied the impact and benefits of using IoT/wearable technologies the teaching process. The method applied in the work was experimental (observation/survey) with 15 children with a mean age of 7.33. The children are more easily motivated in IoT environments and with wearables than playing around a tablet. They concluded that data captured by the wearable and IoT devices can be an invaluable source of information to the instructors.

The role and nature of play in young children's use of toys that connect physical and digital domains has been studied by Marsh [20]. The types of technology used were mainly tablets and apps. The method followed was a survey and direct observation. The survey was carried out with 2000 parents of children aged $0-5$, and they studied a classroom and a single case conducted a direct observation. They found that young children's play increasingly connects digital and nondigital domains and children play connected digital and nondigital components in complex ways. Also, they found that physical and digital domains and the inorganic objects embedded in the electronic toy and the related app were an important element of play. Other research [21] determined the predictive effect of technology use durations of 5-6-year-old children on their social skill levels and social status. The types of technologies studied were television, portable computers, tablets and smartphones. They applied different questionnaires ('Determination of Use of Technology by Children-Parent Form', the 'Social Skills Evaluation Scale', 'The Picture Sociometry Scale', and 'The Personal Information Form') to parents of 162 children aged 5 and 6 years. The main findings of this study include that the use of mobile technologies had no predictive effect on the social skill level, whereas, some mobile devices have predictive effects on the social preference and social impact.

Other researchers [22] identified young children's internet cognition and consequent levels of cyber safety awareness. The technologies analyzed by this study were tablets. They conducted a pilot study as a randomized trial to two groups (experimental and control) formed by 48 children in the intervention group and 22 children in the control group $(n=70)$ and aged between four and five years. The main contribution of this study were that everyday concepts likely to form the basis of young children's thinking about the internet as a platform for cyber safety education in the early years.

Mertala [23] conducted a study about the ideas and wishes of children about using digital media and games in preschool. The types of digital technologies studied were computers, tablets, cameras, and television. The method followed in the study included children's drawings and the tell conversation method (interviews). The sample was formed by 103 children aged 5- 6 years old from five kindergartens. As main results of this work, they found that the $83 \%$ of the children expressed a desire to play digital games in preschool and making games with children is an efficient method for practicing critical game literacy. Also, early childhood educators have reported digital cameras as being motivational and easy to use tools for children and tablets are now mostly used for playing games in preschool and in homes.

\subsubsection{Coding}

In this section we describe the found articles regarding with coding in early childhood education. A research [24] studied the teaching basic object-oriented concepts, coding, and computational thinking using smartphones. They used the observational method. The sample was formed by children aged 
between 4 and 8 years old. They concluded that is possible to introduce object oriented programming concepts into a game-based learning environment in early years.

Other article about coding was presented by Elkin, Sullivan \& Bers [25]. They established the foundational programming concepts using the Robot (KIBO) and the Positive Developmental Technology framework. In the study they observed 64 children aged 3-5 years old from seven classrooms. They concluded that children as young as age 3 could create syntactically correct programs for the KIBO robot, although older preschoolers (closer to age 5) performed better than younger preschoolers on a standardized programming task.

In this sense, other related paper was developed by Bers [44] about the teaching and learning of computational thinking with TangibleK curriculum using robots. The method followed was the iterative testing, analysis, and refinement of an educational intervention conduced with three teachers and 53 children, aged between 4 and 6 years old. The conclusion was that robotic manipulatives allow children to develop fine motor skills and hand-eye coordination while also engaging in collaboration and teamwork. Because the tangible programs and robots exist off-screen, children are drawn to investigate the work of other children, work collaboratively, and negotiate sharing materials, as well as develop their fine motor skills. Children actively engage in problem-solving and learn powerful ideas from computer science and robotics, including core concepts of computational thinking.

\subsubsection{Literacy}

Several articles have analyzed the literacy using technologies in early childhood. An article [27] studied basic literacy skills as well as the teacher's practices and the technology integration of classrooms using tablets (Ipads). They carried out direct observations in classrooms and interviewed four teachers. They found that developmentally appropriate approaches engaged students in child-centered digital production projects.

Other study was carried out by Neumann [9] on emerging literacy skills using tablets. They developed a re-post-test randomized controlled study with 48 children aged 2-5 years. Main conclusion of this work is that tablets can positively support letter name and sound learning and aspects of emergent writing development. Other work [29] studied emergent literacy and early math skills with a group of pre-K students using tablets. Main goals of the study included the use of mobile technology to enhance instruction, use informal feedback from students to guide app selection, and determination of how interactive mobile learning affected academic achievement. They applied the VPK Assessment to two groups (experimental and control) and FLDOE to 28 children ( $4-5$ years old) from two pre-kindergarten classrooms. They found that students can benefit from targeted instruction in the four skill areas assessed in the study (i.e., print knowledge, phonological awareness, mathematics, and oral language) during the pre-K year. They also concluded that mobile learning using informal feedback to guide instruction significantly increased students' phonological awareness and mathematics skills. However, mobile learning using informal feedback from students had no significant effect on students' oral language and their vocabulary skills.

Other researchers, studied the role that digital experiences play in emergent literacy development e-books and digital games [30]. They conducted a literature review about digital texts such as e-books, and concluded that these technologies can foster emergent literacy skills, but the benefits of e-books may be dependent on its quality.

A research [31] studied basic literacy skills and the role 'digital play' in pedagogical interactions using tablets. The researcher conducted a qualitative (semistructured interviews and observations) study with six families (12 parents and 7sevenpreschooler children). Main conclusions included that digital play can be playful and support creativity, encourage exploration and activate real-world connections. Also, mobile and multitouch screens of tablet technologies have changed the way the youngest children interact with images, sounds and ideas. 
Other paper [32] studied tablets and emergent literacy in young children at the home and at preschool classrooms. They conducted a literature review founding that tablets have the potential to foster emergent writing and letter knowledge.

Patchan \& Puranik [33] studied how technology could support young children's emergent writing skills, in particular tablets. They conducted two individual assessments: letter naming and letter writing with 54 preschool children (ages 41-65 months) in 21 small groups. They found that tablets helped students to improve writing, reading, and math abilities. An enhanced tactile experience was more beneficial for learning to write on a tablet computer than increasing the similarity between the practice tasks and the transfer task.

A research [34] tested a tablet intervention designed to improve at-risk preschoolers' mathematics performance (Math Shelf). A randomized controlled trial was carried out with 100 children divided into experimental and control groups. Students experimental group performed statistically significantly better (Cohen's $d=0.57$ ) than comparison students (control group) at posttest.

Miller \& Warschauer [35] studied e-reading using tablets through a literature review. They found that shared-reading interventions can improve oral language and print knowledge of young children. Neumann [36] analyzed the preschoolers' home use of tablets and emergent literacy (writing and reading). Children completed an emergent literacy assessment (print concepts, letter name and sound knowledge, numeral name knowledge, letter writing, and initial phoneme retrieval) at the child's childcare center. Parents completed a home questionnaire about family demographics and home literacy and tablet activities. Fifty-seven children aged between 2 and 4 years old. Positive association found between access to apps and print knowledge. Positive association found between writing with tablets and print and sound knowledge. Tablet writing may be a key activity for early literacy learning.

Neumann [9] conducted a study about the home access and use of tablets for emergent literacy skills (letter name and sound, numeral identification, print concepts and name writing). They assessed 109 children aged between 3 and 5 years old in their preschool and conducted a home questionnaire for parents. No relationships were found between time on tablets and emergent literacy skills. Most parents (69\%) reported that tablets were easy for their child to operate and believed tablets support early literacy development (70\%). Fifty-three percent believed children should have access to tablets at preschool.

A research [37] studied the impact of tablets upon literacy and numeracy, as well other areas of the curriculum. A focus group was conducted with six children of five schools. They found potential conflict from sharing devices. The majority of children expressed a preference for collaborative use. Also, children described literacy activities (such as letter recognition and writing) and numeracy activities (such as matching and ordering) as games.

\subsubsection{Pedagogical Approach}

Regarding the pedagogical approaches, we found in the literature reviewed the followings: Constructionism [44], ADDIE [24], TPACK [38], Self-Determination Theory [45], Positive Technological Development [25,39,45,46], Theory of Mobile Learning [45], and Game-based Learning [24]. Also, Kucirkova [38] proposed guidelines for designing educational apps for Ipads. The researcher carried out a codesign workshop with three teachers. Then, a framework "Research, Practice and Design framework" (iRPD) with key principles for designing educational iPad apps was proposed. Other authors [38] studied the influence of TPACK contextual factors on early childhood educators for tablet use. A survey was conducted with 411 preschool educators serving 3-5-year-olds in school-based, center-based, and head start preschool programs. Main findings were that teachers use different types of apps (literacy, STEM, and general apps) and their attitudes toward the value of technology to aid children's learning are critical to understanding how teachers incorporate tablets into the learning environment. Neumann [47] studied the types of scaffolding behaviors (cognitive, affective, and technical scaffolding) provided by parents during joint tablet activities related to child age and home use. The researcher applied observation and video recording of activities and a questionnaire 
to fifty-five parent-child pairs (mean child age $=3.49$ years). The main conclusion was that younger children require more scaffolding by parents.

An article [45] studied the educational and motivational affordances of tablets apps in 22 children for the teaching and learning of English as foreign language using an exploratory qualitative case study design. The research focused into the study of motivation using the Self-determination theory. The findings indicate that the technological affordances of tablets and their capacity to mediate and encourage social interaction and collaborative learning motivate children to use tablets to learn English both in classroom settings and beyond.

\subsubsection{Other Findings}

Despite the clusters analyzed previously, in the documents [39-43] we found other important results. Sullivan \& Bers [39] studied gender and early childhood technology interventions using robots. They conducted a qualitative research based in interviews (pre-post) and a rubric (Solve-its) with 45 children of 4-7 years old. They found young children were beginning to form opinions about which technologies and tools would be better suited for boys and girls. No significant differences between boys and girls on the robotics and simple programming tasks were found. Boys performed significantly better than girls on the advanced programming tasks such as, using repeat loops with sensor parameters.

Moore \&Adair [40] conducted a qualitative research to analyze social interactions using tablets. The sample was formed by pre-kindergarteners and preservice teachers in early childhood education coursework. They found a variety of spatial arrangements and management of children's engagement with tablets (i.e., some teachers used timers and waiting lists to regulate the amount of time children spent working with digital tools).

Other researchers [41] studied the development of creativity with children aged 3-5 years old using tablets. They analyzed video diaries and observation of the children using tables. Main findings included the tablet offered a mechanism to allow children to articulate their creative play.

Fleer [42] analyzed the relations between play and learning with digital tablets through the video observation of 25 children, aged between 3.3 to 4.4 (mean of 3.8 years). The study found a new kind of relation between play and learning: tablet activity can be conceptualized as consistent and iterative microgenetic movements within a concrete activity setting.

Another authors [43] studied touch interactions (the use of hands and fingers for touching tablets) through video observation of children in a free finger painting activity and coloring in both paper and digital environments. Interactions of eleven children of four years old were analyzed. They found differential benefits and limitations of the use of tablets (or touch screen technologies) in preschool learning contexts, and overall seem to suggest that these technologies should be used as a complement to other activities, without lessening a prioritizing of messy, sensory experiences, such as physical painting, at this stage of child development. And, it seems that the tablet facilitates important mark making activity in preschool children. Also, they found more index finger interaction.

\section{Conclusions}

In this paper we present a systematic review about tangible technologies in childhood education following the method proposed by Tsafnat [16]. After the automatic analysis of 1485 papers with Science Mapping Analysis Software Tool (SciMAT) and a complete analysis of 29 articles we now address the research questions of this work.

RQ1: What tangible technologies have been used in childhood education? If we observe the clustering, the cluster on digital technologies is direct related with RQ1. The most cited words found linked to this cluster were technologies, tablet computers, text, perspective, and collaboration. As we can see, this type of analysis does not tell us so much about the type of technologies used in childhood education. However, in the analysis of documents we found that the tangible technologies used in kindergarten were tablets (in particular Ipads), smartphones, robots, portable computers, 
television, cameras, IoT, and wearables; Regarding the software, the most used were apps, e-books and digital games.

RQ2: What has been the educational use of tangible technologies in childhood? We observe in the clustering that coding is an important area of work in the childhood education, and around it the research is about gender, STEAM, and computational thinking in schools. Additionally, the analysis of documents reaffirms this finding, observing that children using manipulative robots, tablets and smartphones can learn to code, while they are developing fine motor skills, hand-eye coordination, and collaboration, among other skills.

The other main educational use of tangible technologies found through clustering was "literacy". From the words around this cluster (early-childhood, Ipads, mobile technologies, touch-screen tablets and language), only "language" refers to an educational use of tangible technologies. However, in the analysis of documents we found that the tablets helped students to improve writing, reading, and math abilities, and apps, e-books and games has been used as digital tools.

RQ3: What pedagogical approach is behind tangible technologies in childhood education? We found in the clustering the following keywords around pedagogical approach: game-based learning, special needs, classroom, and motivation. However, in the analysis of documents we found several pedagogical approaches and frameworks used in childhood education with tangible technologies: Constructionism, ADDIE, TPACK, Self-Determination Theory, Positive Technological Development, Theory of Mobile Learning, and Game-based Learning. These set of principles has been used in the designing of educational apps by designers, for designing educational activities by teachers or to support scaffolding by parents in home use of educational technologies.

Besides, other research topics related to tangible technologies and childhood education that have been found in this review include gender and early childhood interventions, social interactions, creativity, relation of play and learning, and sensory experiences (uses of hands and fingers for touching).

Finally, note that the results presented in this paper shows the current trends in tangible technologies and childhood education, but, with some limitations, due to the exclusion of papers written in other languages different of English and/or published in journals and conferences not including in the WoS.

Author Contributions: C.S.G.-G.: Conceptualization, Methodology, Formal Analysis, Data Curation, and Writing-Original Draft Preparation. M.D.G.-F. and A.I.-M.: Supervision.

Funding: This research received no external funding.

Conflicts of Interest: The authors declare no conflicts of interest.

\section{References}

1. Blackwell, C.K.; Lauricella, A.R.; Wartella, E. The influence of TPACK contextual factors on early childhood educators'tablet computer use. Comput. Educ. 2016, 98, 57-69. [CrossRef]

2. Ishii, H.; Ullmer, B. Tangible Bits: Towards Seamless Interfaces between People, Bits and Atoms. 1997. Available online: http://gtubicomp2013.pbworks.com/w/file/fetch/65131525/ishii-tangible-bits-chi1997.pdf (accessed on 22 May 2019).

3. Read, J.C.; Markopoulos, P.; Parés, N.; Hourcade, J.P.; Antle, A.N. Child computer interaction. In Proceedings of the Twenty-Sixth Annual CHI Conference Extended Abstracts on Human Factors in Computing Systems (CHI '08), Florence, Italy, 5-10 April; ACM Press: New York, NY, USA, 2008; p. 2419.

4. Hourcade, J.P. Child-Computer Interaction. 2015. Available online: http://homepage.cs.uiowa.edu/ $\sim\{\}$ hourcade/book/child-computer-interaction-first-edition.pdf (accessed on 22 May 2019).

5. Turkle, S. Alone Together: Why We Expect More from Technology and Less from Each Other; Basic Books: New York, NY, USA, 2017; ISBN 9780465093656.

6. Granic, I.; Lobel, A.; Engels, R.C. The benefits of playing video games. Am. Psychol. 2014, 69, 66-78. [CrossRef] [PubMed] 
7. Zuckerman, O.; Arida, S.; Resnick, M. Extending tangible interfaces for education. In Proceedings of the SIGCHI Conference on Human Factors in Computing Systems (CHI '05), Portland, OR, USA, 2-7 April 2005; ACM Press: New York, NY, USA, 2005; p. 859.

8. Nácher-Soler, V.E.; García Sanjuan, F.; Jaén Martínez, F.J. Game Technologies for Kindergarten Instruction: Experiences and Future Challenges. In Proceedings of the II Congreso de la Sociedad Española para las Ciencias del Videojuego (CoSECiVi 2015), Barcelona, Spain, 24 June 2015.

9. Neumann, M.M. An examination of touch screen tablets and emergent literacy in Australian pre-school children. Aust. J. Educ. 2014, 58, 109-122. [CrossRef]

10. Antle, A.N. The CTI framework. In Proceedings of the 1st International Conference on Tangible and Embedded Interaction (TEI '07), Baton Rouge, LA, USA, 15-17 February 2007; ACM Press: New York, NY, USA, 2007; p. 195.

11. Antle, A.N.; Wise, A.F. Getting Down to Details: Using Theories of Cognition and Learning to Inform Tangible User Interface Design. Interact. Comput. 2013, 25, 1-20. [CrossRef]

12. Markova, M.S.; Wilson, S.; Stumpf, S. Tangible User Interfaces for Learning; 2012. Available online: http://openaccess.city.ac.uk/4353/ (accessed on 22 May 2019).

13. Marshall, P. Do tangible interfaces enhance learning? In Proceedings of the 1st International Conference on Tangible and Embedded Interaction (TEI '07), Baton Rouge, LA, USA, 15-17 February 2007; ACM Press: New York, NY, USA; p. 163.

14. Papert, S. Mindstorms: Children, Computers, and Powerful Ideas; Basic Books: New York, NY, USA, 1980; ISBN 0465046274.

15. Read, J.C.; Bekker, M.M. The nature of child computer interaction. In Proceedings of the 25th BCS Conference Human Computer Interaction, Newcastle Upon Tyne, UK, 4-8 July 2011; pp. 163-170.

16. Tsafnat, G.; Glasziou, P.; Choong, M.K.; Dunn, A.; Galgani, F.; Coiera, E. Systematic review automation technologies. Syst. Rev. 2014, 3, 74. [CrossRef]

17. Kay, A. Review: Dynabooks: Past, Present, and Future. Libr. Q. Inf. Community Policy 2000, 70, $385-395$.

18. Martínez, M.A.; Cobo, M.J.; Herrera, M.; Herrera-Viedma, E. Analyzing the Scientific Evolution of Social Work Using Science Mapping. Res. Soc. Work Pract. 2015, 25, 257-277. [CrossRef]

19. de la Guía, E.; Camacho, V.L.; Orozco-Barbosa, L.; Luján, V.M.; Penichet, V.M.; Pérez, M.L. Introducing IoT and Wearable Technologies into Task-Based LanguageLearning for Young Children. IEEE Trans. Learn. Technol. 2016, 9, 366-378. [CrossRef]

20. Marsh, J. The Internet of Toys: A Posthuman and Multimodal Analysis of ConnectedPlay. Teach. Coll. Rec. 2017, 119, 120305.

21. Gülay Ogelman, H.; Güngör, H.; Körükçü, Ö.; Erten Sarkaya, H. Examination of the relationship between technology use of 5-6 year-old children and their social skills and social status. Early Child Dev. Care 2018, 188, 168-182. [CrossRef]

22. Edwards, S.; Nolan, A.; Henderson, M.; Mantilla, A.; Plowman, L.; Skouteris, H. Young children's everyday concepts of the internet: A platform for cyber-safety education in the early years. Br. J. Educ. Technol. 2018, 49, 45-55. [CrossRef]

23. Mertala, P. Fun and games-Finnish children's ideas for the use of digital media inpreschool. Nord. J. Digit. Lit. 2016, 11, 207-226. [CrossRef]

24. Kanaki, K.; Kalogiannakis, M. Introducing fundamental object-oriented programming concepts in preschool education within the context of physical science courses. Educ. Inf. Technol. 2018, 23, 2673-2698. [CrossRef]

25. Elkin, M.; Sullivan, A.; Bers, M.U. Programming with the KIBO Robotics Kit in Preschool Classrooms. Comput. Sch. 2016, 33, 169-186. [CrossRef]

26. Alhinty, M. International Journal of Emerging Technologies in Learning; Kassel University Press: Kassel, Germany, 2015; Volume 10.

27. Lu, Y.-H.; Ottenbreit-Leftwich, A.T.; Ding, A.-C.; Glazewski, K. Experienced iPad-Using Early Childhood Teachers: Practices in theOne-to-One iPad Classroom. Comput. Sch. 2017, 34, 9-23. [CrossRef]

28. Neumann, M.M. Using tablets and apps to enhance emergent literacy skills in youngchildren. Early Child. Res. Q. 2018, 42, 239-246. [CrossRef]

29. Reeves, J.L.; Gunter, G.A.; Lacey, C. Mobile Learning in Pre-Kindergarten: Using Student Feedback to InformPractice. Educ. Technol. Soc. 2017, 20,37-44. 
30. Neumann, M.M.; Finger, G.; Neumann, D.L. A Conceptual Framework for Emergent Digital Literacy. Early Child. Educ. J. 2017, 45, 471-479. [CrossRef]

31. Kervin, L. Powerful and playful literacy learning with digital technologies. Aust. J. Lang. Lit. 2016, 39, 64-73.

32. Neumann, M.M.; Neumann, D.L. The use of touch-screen tablets at home and pre-school to foster emergent literacy. J. Early Child. Lit. 2017, 17, 203-220. [CrossRef]

33. Patchan, M.M.; Puranik, C.S. Using tablet computers to teach preschool children to write letters: Exploring the impact of extrinsic and intrinsic feedback. Comput. Educ. 2016, 102, 128-137. [CrossRef]

34. Schacter, J.; Shih, J.; Allen, C.M.; DeVaul, L.; Adkins, A.B.; Ito, T.; Jo, B. Math Shelf: A Randomized Trial of a Prekindergarten Tablet Number SenseCurriculum. Early Educ. Dev. 2016, 27, 74-88. [CrossRef]

35. Miller, E.B.; Warschauer, M. Young children and e-reading: Research to date and questions for the future. Learn. Media Technol. 2014, 39, 283-305. [CrossRef]

36. Neumann, M.M. Young children's use of touch screen tablets for writing and reading athome: Relationships with emergent literacy. Comput. Educ. 2016, 97, 61-68. [CrossRef]

37. Dunn, J.; Gray, C.; Moffett, P.; Mitchell, D. 'It's more funner than doing work': Children's perspectives on usingtablet computers in the early years of school. Early Child Dev. Care 2018, 188, 819-831. [CrossRef]

38. Kucirkova, N. IRPDA framework for guiding design-based research for iPad apps. Br. J. Educ. Technol. 2017, 48, 598-610. [CrossRef]

39. Sullivan, A.; Bers, M.U. Girls, Boys, and Bots: Gender Differences in Young Children's Performance on Robotics and Programming Tasks. J. Inf. Technol. Educ. Pract. 2016, 15, 145-165. [CrossRef]

40. Moore, H.C.; Adair, J.K. "I'm Just Playing iPad": Comparing Prekindergarteners' and Preservice Teachers' Social Interactions While Using Tablets for Learning. J. Early Child. Teach. Educ. 2015, 36, 362-378. [CrossRef]

41. Arnott, L.; Grogan, D.; Duncan, P. Lessons from using iPads to understand young children's creativity. Contemp. Issues Early Child. 2016, 17, 157-173. [CrossRef]

42. Fleer, M. The demands and motives afforded through digital play in early childhood activity settings. Learn. Cult. Soc. Interact. 2014, 3, 202-209. [CrossRef]

43. Price, S.; Jewitt, C.; Crescenzi, L. The role of iPads in pre-school children's mark making development. Comput. Educ. 2015, 87, 131-141. [CrossRef]

44. Bers, M.U.; Flannery, L.; Kazakoff, E.R.; Sullivan, A. Computational thinking and tinkering: Exploration of an early childhoodrobotics curriculum. Comput. Educ. 2014, 72, 145-157. [CrossRef]

45. Alhinty, M. English-Language Learning at their Fingertips: How Can Teachers UseTablets to Teach EFL Children? Int. J. Mob. Blended Learn. 2015, 7, 45-63. [CrossRef]

46. Bers, M.U.; González-González, C.; Armas-Torres, M.B. Coding as a playground: Promoting positive learning experiences in childhood classrooms. Comput. Educ. 2019, 138, 130-145. [CrossRef]

47. Neumann, M.M. Parent scaffolding of young children's use of touch screen tablets. Early Child Dev. Care 2018, 188, 1652-1662. [CrossRef]

(C) 2019 by the authors. Licensee MDPI, Basel, Switzerland. This article is an open access article distributed under the terms and conditions of the Creative Commons Attribution (CC BY) license (http://creativecommons.org/licenses/by/4.0/). 